\title{
A theory-based approach to analysing conversation sequences
}

\author{
WOLF LANGEWITZ', MATTHIAS NÜBLING², HEIDEMARIE WEBER ${ }^{1}$ \\ 'Division Psychosomatic Medicine, Department of Internal Medicine, University Hospital Basel, Basel, Switzerland \\ ?Society for Empirical Consulting (GEB), Freiburg i. Brsg., Germany
}

\begin{abstract}
SUMMARY. Aims - To assess the quality of communication generally two procedures are used: one defines categories of utterances and counts their frequency, the other uses global observer ratings. We investigated whether a sequence analysis of utterances yields results which more precisely reflect the process of a conversation. Methods - We re-examined data from a randomised controlled intervention study in which residents' interviews with simulated patients were analysed with the Maastricht History and Advice Checklist (MAAS-R) and the Roter Interaction Analysis System (RIAS). Using the U-file of the RIAS we studied the effect of different types of physician questions (open, closed questions, facilitators, other physician actions) on the length of uninterrupted patients' speech and content of utterances. We investigated also whether reciprocity indices improve after a communication skills training, and whether they correlate with global scores form MAAS-R. Results - Patients respond to a closed question with a mean of $1.78( \pm 1.49)$ utterances as compared to $2.75( \pm 2.72)$ utterances after an open question. The likelihood of a concern was more than 10 fold higher after an open question compared to closed questions. Reciprocal sequences make up less than 2 percent of the conversation, Still, they correlate with global items form MAAS-R. The 'empathy index' improves after the training.
\end{abstract}

Declararation of Interest: preparation of the manuscript was supported by a grant from OncoSuisse.

KEY WORDS: communication sequences, communication skills training, Roter Interaction Analysis System, MAAS-R, reciprocal conversation, open questions, patient concerns.

\section{INTRODUCTION}

Current training programs to improve communication skills in physicians use either global scores (e.g. MAAS$\mathrm{R}$ in Langewitz et al., 1998) or count the frequency of certain types of utterances (e.g. RIAS in Levinson \& Roter, 1993) to evaluate the impact of the intervention. Even though global scores have high interrater reliability (see Langewitz et al., 1998) little is known about the very elements of a communication that lead to a high score $\mathrm{e}$. g. in the dimension "physician takes up emotions" from MAAS-R (van Thiel, 1991). During rater training and in numerous feedback rounds with residents it occurs that some interviews contain but one outstanding moment of perfect match between patient and physician and thus are perceived as a good example of patient-oriented communication. Whereas this lucky punch in communication might get picked up by global rating scales it will submerge in the vast amount of simple conversational acts relating to the task of asking for and giving information. Therefore, evaluation instruments like RIAS (e.g. Roter \& Larson, 2002) might well miss these important events if they only rely on frequency counts. This paper descri-

Address for correspondence: Professor Dr. Wolf Langewitz, Petersgraben 4, CH-4031 Basel (Switzerland).

E-mail: wlangewitz@uhbs.ch bes another approach which we hope combines the ability of global scales to mirror rare but important events and the precision of linguistic instruments to mirror more precisely the flow of utterances.

First, we defined which sequences in physician or patient utterances demonstrate most apparently a patientcentred communication. Even though a precise definition of this concept is still lacking (e.g. Mead \& Bower, 2002) we might assume that physicians using this approach in communication are interested in their patients' understanding of their disease or illness (Smith \& Hoppe, 1991), they wonder whether patients understand the information they give them (Schillinger et al., 2003), and they care for their patients concerns.

Open questions are thought to help patients tell their story (Delbanco, 1992). Therefore we analysed whether open questions do actually help patients into lengthier statements and whether the statements responding to an open question contain other information than those following a closed question. Furthermore, we were interested to see whether sequences can be identified during which physician and patient interact in a reciprocal manner. We defined reciprocity as follows:

- After information giving or counselling, the physician gives the patient a chance to react by showing signs of agreement, concern, asking for reassurance, etc.

- When a patient has introduced concern or has been asking for reassurance the physician responds in an empathic way or by trying to keep the problem situa- 
tion open for further communication by giving orienting responses or checking back what he has just heard.

In order to validate these reciprocity indices we used a data set which had been described five years ago (Langewitz et al., 1998) in a randomised controlled study assessing an intervention program to improve communication skills of residents in Internal Medicine. Thus, we were able to correlate reciprocity indices with patient satisfaction, global ratings from MAAS-R and to analyse whether physicians from the intervention group were successful in showing more reciprocal behaviour after the intervention than the control group.

\section{METHODS}

\section{Study population and study design}

Of 54 residents, who were working at the Department of Internal Medicine at our hospital, 47 were illegible, three refused participation, and one left the clinic before the intervention started. 23 residents were randomised into the control group, 20 into the intervention group, one resident from the intervention group left the hospital before completion of the study and was lost to follow up. The control group received the standard medical training offered to all residents: 6.5 hours per week on the average, the intervention group received the standard training plus a specific intervention of 15 to 20 hours duration described in more detail in Langewitz et al. (1998).

\section{Evaluation of the intervention}

Pre- and post-intervention interviews with simulated patients were compared; each resident performed two interviews which were rated by three independent raters to yield MAAS-R scores. The same interviews were now reassessed by two student raters according to a German translation of the RIAS Handbook. For the current analyses the so called U-file of RIAS was used: this file contains the sequence of utterances of patient and physician (see table I). It was subjected to SPSS-based sequence analysis which is explained in the next paragraph.

For the current analysis the mean of two interviews and three raters was used to yield MAAS-R scores, the mean of two simulated patients' scores in patient satisfaction questionnaires was used to yield a patient satisfaction score (PSQ; Mathews \& Feinstein, 1989; Langewitz et al., 1995), whereas the U-file of two interviews and only one rater was chosen to yield RIAS Ufiles. The reason for the latter approach is that $U$-files are unique: even though different raters counted almost the same number of total utterances (mean number of utterances in the whole file: rater $1: 259 \pm 27$, rater 2: $256 \pm$ 29; Spearman rank correlation coefficient $r=.99$ ) and utterances in single categories (e.g. Physician gives medical information: rater 1: $11.7 \pm 10.9$, rater 2: $10.9 \pm$ 9.9; Spearman rank correlation coefficient $r=.99$ ) there are minute differences in the sequence of utterances which make the use of any averaging procedure impossible.

\section{SPSS-based Data Organisation and Data Analysis}

Data was passed from the different RIAS U-files containing one interview each to an SPSS database containing all the utterance data as well as structural data (i.e. doctor's sex, etc.). String-variables were transformed to numerical coding.

In a first step a variable "action" was formed out of actor ("direction" in RIAS) and utterance (table I).

\section{Analyses of actions:}

This level of data organisation allows frequency counts of the different actions on various levels:

- Segments of the interview vs. the whole interview,

- all interviews of one physician,

- groups of interviews (e.g. all post-intervention interviews).

Another possibility is the comparison of interviews or physicians according to the frequency of certain actions (e.g. physicians who use more open questions compared to the rest).

\section{Analyses of groups of actions:}

Depending on the hypotheses it may be helpful to group some codes of the detailed RIAS coding scheme under more general terms. If for instance the focus of the analysis lies on the type of the questions raised by the physician and not on it's exact content like open psychosocial or open medical question categories can be grouped to analyse the difference between open question and closed question in general.

\section{Analyses of sequences of actions:}

Sequences of actions are chains of two or more actions. The simplest sequence consists of two neighbours, a predecessor and a successor. In terms of causality (the predecessor causes the successor) they can also be called "given" and "target" or more statistically "predictor" and "criterion".

Except for the first action in an interview every action has a preceding neighbour. Therefore, the number of sequences (with two actions) is equal to the total number 
Table I. - Data organisation in RIAS U-file and SPSS-data-file: Utterance content and direction of utterance (coded as strings) are numerically coded and concatenated to "actions" (last column), containing the actor (= direction of action, Ist digit, Doctor $=1$, Patient $=2$ ) and utterance content ( $=$ numerical code of utterance, 2 nd and $3 \mathrm{rd}$ digit) in SPSS.

\begin{tabular}{|c|c|c|c|c|c|c|}
\hline File No. & $\begin{array}{l}\text { Direction } \\
\text { (RIAS) }\end{array}$ & $\begin{array}{l}\text { Utterance content } \\
\text { (RIAS) }\end{array}$ & $\begin{array}{l}\text { Utterance number } \\
\text { (SPSS) }\end{array}$ & $\begin{array}{c}\text { Actor Code } \\
\text { (SPSS) }\end{array}$ & $\begin{array}{l}\text { Utterance code } \\
\text { (SPSS) }\end{array}$ & $\begin{array}{c}\text { Action code } \\
\text { (SPSS) }\end{array}$ \\
\hline 1 & $\mathrm{D}>\mathrm{P}$ & personal & 1 & 1 & 1 & 101 \\
\hline 1 & $D>P$ & personal & 2 & 1 & 1 & 101 \\
\hline 1 & $P>D$ & personal & 3 & 2 & 1 & 201 \\
\hline 1 & $D>P$ & ?med & 4 & 1 & 29 & 129 \\
\hline 1 & $P>D$ & concern & 5 & 2 & 8 & 208 \\
\hline 1 & $\mathrm{D}>\mathrm{P}$ & GIVES-med & 6 & 1 & 12 & 112 \\
\hline$\ldots$ & $\ldots$ & $\ldots$ & $\ldots$ & $\ldots$ & $\ldots$ & $\ldots$ \\
\hline 1 & $P>D$ & ?med & 59 & 2 & 29 & 229 \\
\hline 1 & $\mathrm{D}>\mathrm{P}$ & GIVES-med & 60 & 1 & 12 & 112 \\
\hline 1 & $\mathrm{D}>\mathrm{P}$ & personal & 61 & 1 & 1 & 101 \\
\hline 2 & $\mathrm{D}>\mathrm{P}$ & personal & 1 & 1 & 1 & 101 \\
\hline 2 & $P>D$ & personal & 2 & 2 & 1 & 201 \\
\hline 2 & $P>D$ & [?]AG/soc & 3 & 2 & 28 & 228 \\
\hline 2 & $P>D$ & GIVES-med & 4 & 2 & 12 & 212 \\
\hline
\end{tabular}

of actions minus one for every interview.

Sequences are not limited to two actions, they can go forward (lead) or backward (lag) and cover several actions in both directions.

\section{Analyses of lengths of defined chains:}

Another possibility is the analysis of the length of defined chains. One example is the counting of the number of consecutive, uninterrupted patient actions. The counter is assigned to the last physician action preceding a single or a sequence of patient actions thus, allowing for the analysis of the question whether certain physician actions cause longer sequences of patient utterances.

The example in table II shows that in file No. 1 the counter has the value of 1 for action number 2 and action number 4 because only one utterance of the patient follows, whereas in file No. 2 the counter is set to 3 in action number 1 , signifying a sequence of 3 uninterrupted patient utterances.
The most promising results are obtained by combining these possibilities of data organisation and data analyses. For instance: first grouping, than doing sequence analysis and calculating counters.

\section{Statistical analyses}

Statistical analyses included frequencies, bivariate crosstabs and analysis of variance with one factor as well as multivariate analysis, i.e. analysis of variance with two and more factors, simple and multiple linear and logistic regression analysis. All analyses were run on SPSS.

\section{DEFINITION OF RECIPROCAL CONVERSATION}

Assuming that good non-instrumental conversation (Bensing \& Langewitz, 2002) is characterised by the physician's ability to respond to patients " voicing concern or

Table II. - Possibilities of data organisation in SPSS: actions, sequences (two actions) and counters (i.e.: number of patient reactions).

\begin{tabular}{|c|c|c|c|c|c|c|}
\hline File No. & Utterance number & Actor Code & Utterance code & $\begin{array}{l}\text { Action code } \\
\text { (SPSS) }\end{array}$ & $\begin{array}{c}\text { Sequence } \\
\text { (pred. - succ.) }\end{array}$ & $\begin{array}{c}\text { Counter } \\
\text { (Pat. reactions) }\end{array}$ \\
\hline 1 & 1 & 1 & 1 & 101 & - no pred. & 0 \\
\hline 1 & 2 & 1 & 1 & 101 & 101101 & 1 \\
\hline 1 & 3 & 2 & 1 & 201 & 101201 & 0 \\
\hline 1 & 4 & 1 & 29 & 129 & 201129 & 1 \\
\hline 1 & 5 & 2 & 8 & 208 & 129208 & 0 \\
\hline 1 & 6 & 1 & 12 & 112 & 208112 & 0 \\
\hline ... & $\ldots$ & $\ldots$ & $\ldots$ & $\ldots$ & $\ldots$ & $\ldots$ \\
\hline 1 & 59 & 2 & 29 & 229 & $\ldots$ & 0 \\
\hline 1 & 60 & 1 & 12 & 112 & 229112 & 0 \\
\hline 1 & 61 & 1 & 1 & 101 & 112110 & 0 \\
\hline 2 & 1 & 1 & 1 & 101 & - no pred. & 3 \\
\hline 2 & 2 & 2 & 1 & 201 & 101201 & 0 \\
\hline 2 & 3 & 2 & 28 & 228 & 201228 & 0 \\
\hline 2 & 4 & 2 & 12 & 212 & 228212 & 0 \\
\hline
\end{tabular}


asking for reassurance we analysed whether these utterances are followed by physicians either reacting with empathy immediately (physician categories: approve, empathy/legitimate, concern, reassurance, partnership statements, self-disclosure, agree) or by keeping the issue open for further elaboration by using the categories checking, orientation, asking for patients' opinion.

Another possibility to describe a more patient centred consultation concerns the physician's willingness to invite a response from the patient after information giving or counselling. This index was defined as a sequence of physician giving information or counselling followed by patients' responses with the categories: approve, concern, agree, asking closed or open questions, asking for service, asking for permission, asking for reassurance.

\section{RESULTS}

At the time of the intervention residents in the control and intervention group did not differ in any demographic variable including age, gender distribution, experience in Internal Medicine, time since final examination, etc.

\section{Characteristics of open questions}

For the analysis of the effects of open questions a total number of 38869 utterances in 163 interviews was used.

As table III shows most of these utterances occur in few categories, mainly asking for information and giving information or counselling on the physicians' side and giving information on the patients' side. The category physician facilitators includes utterances of the type approve, agree, back-channel, and checking.

As table IV shows half of the open questions a physician is asking is concerned with medical information.

\section{Open and closed questions and their consequences}

This analysis was restricted to physician actions, where the patient was reacting at least with one action. Within loops of physician actions (e.g. physician giving information - physician giving information - physician ...) only the last action passing over the lead of conversation to the patient was analysed.

Following a closed question from the physician patients respond with a mean of $1.78( \pm 1.49 ; \mathrm{N}=7030)$ utterances as compared to $2.75( \pm 2.72 ; \mathrm{N}=905)$ utterances after an open question. The mean number of patient responses to facilitating physician utterances was $1.65 \pm$ $1.49(\mathrm{~N}=2452)$. To other physician actions patients responded with $1.43( \pm 1.49)$ utterances $(\mathrm{N}=1741)$. ANOVA shows that the type of question has a significant effect on the number of patient responses $(F=142, d f=3$, $\mathrm{p}<0.0001$ ).

We further analysed whether the type of information given is determined by the character of the physicians' questions. Table $\mathrm{V}$ lists all patient utterances in the area of information giving and voicing concern $(\mathrm{N}=12.127)$ which follow immediately after physicians actions as listed in the table.

As table V shows 68.3 percent of a total of 7030 closed questions (followed immediately by a patient action) elicit medical information and 0.4 percent elicit patients concern. Open questions yield medical information in $42.9 \%$ and patients ${ }^{\circ}$ concern in $11.6 \%$. Thus, open que-

Table III. - Distribution of common physician and patient actions.

\begin{tabular}{lll}
\hline Type of Action - Summary & Number & Percent \\
\hline Open questions physician & 942 & 2.4 \\
Closed questions physician & 7219 & 18.6 \\
Facilitators physician & 3852 & 9.9 \\
Physician giving information & 2316 & 6.0 \\
Other action physician & 3007 & 7.8 \\
Patients giving medical information & 10688 & 27.5 \\
Patients giving therapeutic information & 1123 & 2.9 \\
Patients giving life style/psychosocial information & 4145 & 10.7 \\
Other actions patient & 5577 & 14.2 \\
Total utterances & 38869 & 100.0 \\
\hline
\end{tabular}

Table IV. - Distribution of types of open questions physician.

\begin{tabular}{lll}
\hline Physician: Open Question-Details & Number & Percent \\
\hline Asks for medical information & 453 & 48.1 \\
Asks for therapeutic information & 50 & 5.3 \\
Asks for life style/psychosocial information & 198 & 21.0 \\
Asks for patient opinion & 238 & 25.3 \\
Asks for other information & 3 & 0.3 \\
Total Open questions physician & 942 & 100.0 \\
\hline
\end{tabular}


A theory-based approach to analysing conversation sequences

Table V. - The dependence of information given and type of question from the physician.

\begin{tabular}{|c|c|c|c|c|c|c|c|c|}
\hline \multirow{2}{*}{$\begin{array}{l}\text { Type of information } \\
\text { given from patient } \\
\text { Medical info \# }\end{array}$} & \multicolumn{2}{|c|}{$\begin{array}{l}\text { Physician closed question } \\
\qquad(\mathrm{N}=7030)\end{array}$} & \multicolumn{2}{|c|}{$\begin{array}{l}\text { Physician open question } \\
(\mathrm{N}=905)\end{array}$} & \multicolumn{2}{|c|}{$\begin{array}{l}\text { Physician facilitators } \\
\qquad(\mathrm{N}=2452)\end{array}$} & \multicolumn{2}{|c|}{$\begin{array}{l}\text { Physician other actions } \\
(\mathrm{N}=1740)\end{array}$} \\
\hline & 4803 & $\Rightarrow 68.3 \%$ & 388 & $\Rightarrow 42.9 \%$ & 378 & $\Rightarrow 15.4 \%$ & 104 & $\Rightarrow 6.0 \%$ \\
\hline Therapeutic info \# & 438 & $\Rightarrow 6.2 \%$ & 48 & $\Rightarrow 5.3 \%$ & 39 & $\Rightarrow 1.6 \%$ & 20 & $\Rightarrow 1.1 \%$ \\
\hline Life style/psycho-social info \# & 1590 & $\Rightarrow 22.6 \%$ & 191 & $\Rightarrow 21.1 \%$ & 114 & $\Rightarrow 4.6 \%$ & 43 & $\Rightarrow 2.5 \%$ \\
\hline Concern \# & 29 & $\Rightarrow 0.4 \%$ & 105 & $\Rightarrow 11.6 \%$ & 40 & $\Rightarrow 1.6 \%$ & 100 & $\Rightarrow 5.7 \%$ \\
\hline
\end{tabular}

\# Chi2 (Pearson): $\mathrm{p}<0.0001$

Table VI. - Intervention effects upon reciprocity indices.

\begin{tabular}{llll}
\hline Group & $\begin{array}{l}\text { Patient reactions to } \\
\text { physician info or counselling }\end{array}$ & $\begin{array}{l}\text { Physician empathy } \\
\text { keeping situation open }\end{array}$ & Physician empathy or \\
\hline Control $(\mathrm{N}=23)$ & $1.25 \pm 0.7 \%$ & $0.49 \pm 0.44 \%$ & $0.52 \pm 1.11 \%$ \\
lntervention $(\mathrm{N}=19)$ & $1.20 \pm 0.5 \%$ & $0.43 \pm 0.41 \%$ & $0.65 \pm 0.90 \%$ \\
ANOVA & n.s. & n.s. & $\mathrm{F}(1)=5.00 ; \mathrm{p}=0.031$ \\
\hline
\end{tabular}

stions are much more potent in this regard and not that bad in eliciting medical information as their immediate successor. The other physician categories are on the average less potent in eliciting any type of information. Note that the table only contains patient responses in the categories listed, therefore the sum of the columns does not equal the total number of questions asked.

\section{Reciprocity indices}

We defined reciprocal sequences first, as those sequences where physicians give patients the chance to respond when they had received information or counselling from the physician, and second, as the physician's ability to react to patients voicing concern or asking for reassurance (see methods for details).

Table VI shows the distribution of these reciprocity indices divided into control and intervention group using post intervention data only and based upon the physician as unit of analysis ( $\mathrm{N}=42 ; 20313$ utterances).

Sequences qualifying for any of the indices are low in both groups showing an intervention effect in the Sumindex only: physicians in the intervention group show more empathy plus keeping the situation open than physicians in the control group.

We then correlated these indices with data from the Revised Maastricht History and Advice Checklist (MAAS-R): The percentage of patients' reactions to information giving or counselling correlated with the global scores 'patient-centred communication' ( $r=31$; $p=0.045$ ), 'patient participation in decision making' $(\mathrm{r}=.37 ; \mathrm{p}=0.017)$, and with the sum score of patient satisfaction $(r=.38 ; p=0.022)$. The sum score of physician empathy or keeping the situation open correlated with 'patient-centred communication' $(\mathrm{r}=.30 ; \mathrm{p}=0.054)$, 'patient participation in decision making' $(\mathrm{r}=.35$; $\mathrm{p}=0.025$ ), and with the sum score of patient satisfaction $(r=.29 ; p=0.092)$. It further correlated with the correspon- ding item in the MAAS- $\mathrm{R}$ 'taking up emotions' $(\mathrm{r}=.36$; $\mathrm{p}=0.018$ ).

\section{DISCUSSION}

Open questions are not simply the philosopher's stone. The increase in the number of patients' responses to physicians asking open questions is not as striking as anticipated. However, our analyses show that open questions yield relevant information especially in the psychosocial domain. This corroborates earlier findings from Levinson \& Roter (1993) and Roter \& Hall (1992).

The definition of reciprocity indices yields a low number of sequences fulfilling the criteria of reciprocity. Still, the correlation with external scales rated from different raters, based on two interviews per resident points to the validity of these new indices. They might form part of those rare but important events during a communication - the above quoted lucky punch - which turns an average or bad communication into a perfect match between patient and physician.

This is a preliminary analysis of a new approach to analysing the sequence of utterances during a conversation. Therefore, the main short-comings of the definition of the so-called reciprocity indices and of the type of analyses applied should be mentioned in some detail:

The definition of reciprocal conversation might seem rather arbitrarily. However, other research has shown that it is important to recognise patients' emotions and to respond appropriately to them. As emotional distress often goes unrecognized (Del Piccolo et al., 2000) increasing physicians' awareness of their patients' emotions and encouraging them to react seems warranting. Furthermore, the low level of comprehension of information given e.g. in pre-operative visits (Krupp et al., 2000) points to the necessity to check precisely whether or not a patient 
understands what he or she was told. We did not assume that there would be a single most profitable way for patients to respond, we simply were looking for any reaction of working with the information just given be it by means of a comment or by means of raising another topic.

We have presented a theory-driven approach to analysing sequences of utterances defining 'good conversation' in a rather restrictive way. One might as well use a completely different empirical approach, analysing sequences without any a priori hypothesis (Sandvik et al., 2002; Del Piccolo et al., 2000). Explorative analyses first look at the question "what is in the data" to then generate hypotheses, our theory driven analysis goes the other way round.

A major short coming of the analyses presented here is the lack of analysing more distant neighbours. It might well be possible that e.g. a patient's concern elicits a physician's response with a certain delay, e.g. with a lag of three interspersed physician utterances; or that the patient concludes his or her segment of utterances which contained a concern with non-concern or neutral actions weakening the intensity of his or her complaints. These sequences would be missed in our approach which is looking for immediate successors of certain physician or patient actions. One might argue however, that a physician who never responds to a patient who ends his or her statement with a sentence asking for reassurance is not very likely to respond to this type of patient question when it is embedded in other utterances making its 'detection' more difficult. On the other hand it is likely that physicians who respond to concerns or asking for reassurance or other demands from the patient immediately do so with a certain delay i.e. after a certain 'utterance-lag' also. Thus, the difference between lag- 1 and lag-n studies might not be as fundamental as one might assume. A basic problem with longer lags exists in so far as the causal attribution of a certain utterance as being the consequence of another becomes very fragile if some 'neutral' (non-target) utterances occurred in between. This phenomenon might rather reflect the effect of basic changes in the atmosphere of a conversation than a cause - effect relationship. We assume that within a conversation changes in the atmosphere or as one might say in the conversational microclimate occur. In accordance with these changes there should be clusters of certain types of interactions some being more reciprocal and others being more of the simple type asking for information - giving information. Further analyses should investigate how this cluster phenomenon could best be defined and whether it can be predicted by certain shifts in the conversational micro-climate.

\section{REFERENCES}

Bensing J.M. \& Langewitz W. (2002). Die ärztliche Konsultation. In Psychosomatische Medizin, $6^{\text {th }}$ ed. (ed. T. von Uexküll et al.), pp. 415-414. Urban \& Fischer: Munich.

Delbanco T.L. (1992). Enriching the doctor-patient relationship by inviting the patient's perspective. Annals of Internal Medicine 116, 414 418.

Del Piccolo L., Saltini A., Zimmermann C, \& Dunn G. (2000). Differences in verbal behaviours of patients with and without emotional distress during primary care consultations. Psychological Medicine 30, 629-643.

Krupp W., O. Spanehl, W. Laubach \& V. Seifertet (2000). Informed consent in neurosurgery: patients' recall of preoperative discussion. Acta Neurochirurgica 142, 233-239.

Langewitz W., Keller A., Denz M., Wossmer-Buntschu B. \& Kiss A. (1995). Patienten Zufriedenheits-Fragebogen (PZF): Ein taugliches Mittel zur Qualitätskontrolle der Arzt-Patient-Beziehung? [The Patient Satisfaction Questionnaire: a suitable tool for quality control in the physician-patient relationship?]. Psychotherapie, Psychosomatik, Medizinische Psychologie 45, 351-357.

Langewitz W.A., Eich P., Kiss A. \& Wossmer B. (1998). Improving communication skills--a randomized controlled behaviorally oriented intervention study for residents in internal medicine. Psychosomatic Medicine 60, 268-276.

Levinson W. \& Roter D. (1993). The effects of two continuing medical education programs on communication skills of practicing primary care physicians. Journal of General Internal Medicine 8, 318-324.

Matthews D.A. \& Feinstein A.R. (1989). A new instrument for patients' ratings of physician performance in the hospital setting. Journal of General Internal Medicine 4, 14-22.

Mead N. \& Bower P. (2002). Patient-centred consultations and outcomes in primary care: a review of the literature. Patient Education and Counseling 48, 51-61.

Roter D.L. \& Hall J.A. (1992). Doctors Talking with Patients/Patients Talking with Doctors: Improving Communication in Medical Visits. Auburn House: Westort CT.

Roter D. \& Larson S (2002). The Roter interaction analysis system (RIAS): utility and flexibility for analysis of medical interactions. Patient Education and Counseling 46, 243-251.

Sandvik M., Eide H., Lind M., Graugaard P.K., Torper J. \& Finset A. (2002). Analyzing medical dialogues: strength and weakness of Roter's interaction analysis system (RIAS). Patient Education and Counseling 46, 235-241.

Schillinger D., Piette J., Grumbach K., Wang F., Wilson C., Daher C., Leong-Grotz K. \& Castro C. \& Bindman A.B. (2003). Closing the loop: physician communication with diabetic patients who have low health literacy. Archives of Internal Medicine 163, 83-90.

Smith R.C. \& Hoppe R.B. (1991). The patient's story: integrating the patient- and physician-centered approaches to interviewing. Annals of Internal Medicine 115, 470-477.

van Thiel J., Kraan H.F. \& Van Der Vleuten C.P. (1991). Reliability and feasibility of measuring medical interviewing skills: the revised Maastricht History-Taking and Advice Checklist. Medical Education 25, 224-229. 